\title{
The DNMT3B -579 G>T promoter polymorphism and risk of lung cancer
}

\author{
HUI LIU ${ }^{1,2}$, YIFEI JIAO ${ }^{1}$, YANA GUAN ${ }^{1}$, YINGBIN LAO ${ }^{1}$, CHENGCHENG ZHAO $^{1}$ and HONG FAN ${ }^{1}$ \\ ${ }^{1}$ Department of Genetic and Developmental Biology, Medical School of Southeast University, Nanjing 210009; \\ ${ }^{2}$ The Third Affiliated Hospital of Harbin Medical University, Harbin 150081, P.R. China
}

Received August 31, 2011; Accepted November 1, 2011

DOI: $10.3892 /$ etm.2011.420

\begin{abstract}
The present study aimed to investigate the association of the $-579 \mathrm{G}>\mathrm{T}$ polymorphism in the DNMT3B promoter with susceptibility to lung cancer. A total of 174 lung cancer patients and 135 healthy controls from the northern part of China were enrolled, and were matched for gender and age. All subjects were genotyped by polymerase chain reaction-restriction-fragment length polymorphism analysis and confirmed by DNA sequencing. Stratification analyses were used to study the subgroups of subjects by age and gender, and evaluate the association between the $-579 \mathrm{G}>\mathrm{T}$ polymorphism and the genetic susceptibility to lung cancer. The results revealed that individuals with the DNMT3B -579 GT genotype had a significantly decreased risk of lung cancer [odds ratio (OR), $0.517 ; 95 \%$ confidence interval (CI), 0.273-0.981] compared with those with a -579 TT genotype in the studied population. However, the deviation was significant (OR, 0.138, 95\% CI, 0.034-0.549) between the risk of lung cancer and the GT and GG genotype, when the smoking factor was considered. The data from this study indicate that the DNMT3B genetic polymorphism varies among various races, ethnic groups and geographical areas. The DNMT3B $-579 \mathrm{G}>\mathrm{T}$ polymorphism may contribute to the genetic susceptibility to lung cancer.
\end{abstract}

\section{Introduction}

In China, lung cancer remains one of the most common types of malignancy in males and females. In the past decade, the morbidity and mortality of lung cancer have markedly increased (1). Numerous studies have shown that genetic factors contribute to the risk of lung cancer development (2-4); although smoking is also a factor that is involved. Greater abnormal DNA methylation was investigated in lung carcinogenesis,

Correspondence to: Professor Hong Fan, Department of Genetic and Developmental Biology, Medical School of Southeast University, Nanjing 210009, P.R. China

E-mail: fanh@seu.edu.cn

Key words: lung cancer, DNMT3B, DNA methylation, single nucleotide polymorphism, polymerase chain reaction-restriction fragment length polymorphism suggesting that epigenetic factors are crucial in determining an individuals' susceptibility to lung cancer $(5,6)$.

DNA methylation is a major epigenetic modification that regulates gene expression and chromosomal stability $(7,8)$. Consequently, aberrant DNA methylation is related to various tumors $(7,9)$. DNA methylation is mediated by DNA methytransferases (DNMTs). In humans, three DNMTs are catalytically active, including DNMT1, DNMT3A and DNMT3B (10-11). DNMT1 is largely responsible for pre-exsiting methylation following DNA replication (12). DNMT3A and DNMT3B are required for de novo methylation (13). Hypomethylation may be related to chromosomal instability, loss of imprinting and reactivation of transposable elements. Hypermethylation may increase susceptibility to environmental carcinogens $(14,15)$. Studies have also indicated that DNMTs are up-regulated in various human cancers, which may be associated with aberrant methylation $(14,16)$.

Recently, certain candidate single nucleotide polymorphisms (SNPs) in the DNMT3B gene have been deposited in public databases (http://www.ncbi.nlm.nih.gov/SNP). Previous studies have indicated that these variants may modulate the susceptibility to cancer by influencing DNMT3B activity in DNA methylation $(14,17) .-579 \mathrm{G}>\mathrm{T}$ is a single SNP in the promoter region of the DNMT3B gene, which may modify susceptibility to tumors $(18,19)$. DNMT3Bs are the predominant expression forms of DNMT3B in human lung cancer and, in part, are involved in the epigenetic silencing of RASSF1A (20). DNMT3B proteins were highly expressed in a coordinate manner in lung tumors, particularly in smokers, and overexpression may result in promoter hypermethylation of multiple tumor suppressor genes (TSGs), ultimately leading to lung tumorigenesis and poor prognosis (21). Studies have revealed that the $-579 \mathrm{G}>\mathrm{T}$ polymorphism is associated with susceptibility to gastric cancer (22), head, neck (23) and colon cancer (19). Previously, contradictory conclusions have been made regarding the association of the $-579 \mathrm{G}>\mathrm{T}$ polymorphism with lung cancers. The present study investigates the frequency of the DNMT3B -579 G>T polymorphism in a Northeastern Chinese population, and susceptibility to lung cancer.

\section{Materials and methods}

Study population. This case-control study included 174 lung cancer patients and 135 healthy controls. Eligible cases included 


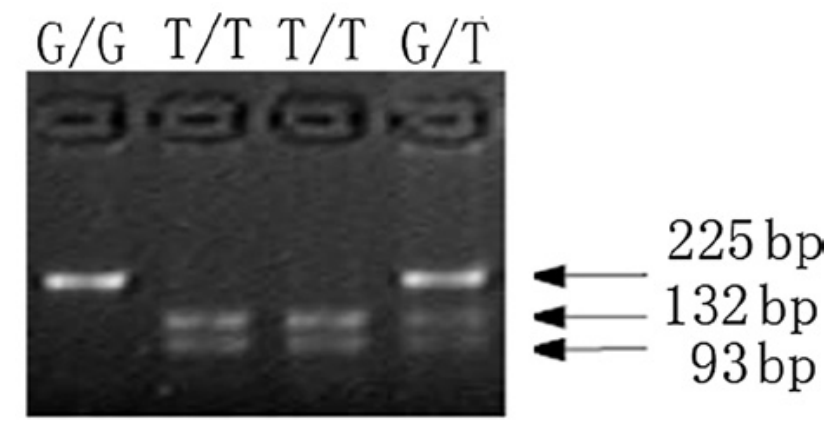

Figure 1. Polymerase chain reaction-restriction fragment length polymorphism genotyping of DNMT3B 579 G>T. GG, wild type; GT, heterozygote; TT, variants.

181 patients histopathologically confirmed during surgery at Harbin Medical University Cancer Hospital, China, in 2009. However, 7 cases were excluded for not having accurate information. The controls were randomly selected from healthy individuals who visited the same hospital for regular physical check-ups during the same period. We defined a healthy subject as a person free of disease (including no history of cancer) upon the health check-up. The controls and cases were well matched for age and gender. All cases and controls were ethnically Chinese and resided in Harbin or its surrounding regions. A questionnaire regarding smoking was also completed for each case and control.

DNA extraction. The collected sera were mixed with ethylenediaminetetraacetic acid (EDTA) and then stored at $4^{\circ} \mathrm{C}$ in blood vacuum tubes. Genomic DNA was then extracted within 1 week of sample collection by proteinase $\mathrm{K}$ digestion, as previously described (24).

DNMT3B genotyping. DNMT3B -579 G>T polymorphisms were determined by polymerase chain reaction-restriction fragment length polymorphism (PCR-RFLP) assay as previously described (25). PCR was performed in a volume of $25 \mu \mathrm{l}$ containing $100 \mathrm{ng}$ of DNA template, 10X PCR Master Mix (Promega, Madison, WI, USA) and $10 \mathrm{pmol} / 1$ each of sense primer (5'-GAGGTCTCATTATGCCTAGG-3') and antisense primer (5'-GGGAGCTCACCTTCTAGAAA-3'). PCR cycle conditions consisted of an initial denaturation at $94^{\circ} \mathrm{C}$ for $5 \mathrm{~min}$, followed by 30 cycles at $94^{\circ} \mathrm{C}$ for $30 \mathrm{sec}$, at $57^{\circ} \mathrm{C}$ for $30 \mathrm{sec}$, at $72^{\circ} \mathrm{C}$ for $30 \mathrm{sec}$ and a final extension at $72^{\circ} \mathrm{C}$ for $7 \mathrm{~min}$. The 225-bp fragment was then digested with 5 units of PuvII (New England Biolabs, Beverly, MA, USA) overnight at $37^{\circ} \mathrm{C}$. The digested products were then separated on $2 \%$ agarose gels. RFLP bands were visualized under ultraviolet (UV) lights with ethidium bromide staining. The DNMT3B T/T genotype was expected to show 2 DNA bands at the positions of 132 and $93 \mathrm{bp}$, respectively, whereas the $\mathrm{G} / \mathrm{G}$ genotype was expected to show a single band (225 bp) and the heterozygote was expected to have 3 bands (225, 132 and 93 bp) (Fig. 1). For quality control, genotyping analysis was performed blindly with respect to case/control status and repeated twice for all subjects.

DNA sequencing analysis. To confirm the genotyping results, PCR-amplified DNA samples were selected and examined by
Table I. Distribution of selected variables in lung cancer patients and control subjects.

\begin{tabular}{lccc}
\hline Variables & $\begin{array}{c}\text { Patients (\%) } \\
(\mathrm{n}=174)\end{array}$ & $\begin{array}{c}\text { Control (\%) } \\
(\mathrm{n}=135)\end{array}$ & P-value \\
\hline Age (years) & & & 0.052 \\
$<45$ & $25(14.4)$ & $31(23.0)$ & \\
$\geq 45$ & $149(85.6)$ & $104(11.0)$ & \\
Gender & & & 0.051 \\
Male & $107(61.5)$ & $68(50.4)$ & \\
Female & $67(38.5)$ & $67(49.6)$ & \\
\hline
\end{tabular}

DNA sequencing. The PCR fragments were recovered from the agarose gel followed by purification with the Promega DNA Clean-up Kit (Wizard SV Gel and PCR Clean-up System, Promega) and DNA sequences of the PCR products were determined using the Applied Biosystems Prism DNA Sequencer (Model 377; PE Applied Biosystems, Warrington, UK). The results obtained from the DNA sequencing analysis confirmed the reliability of the genotyping assay.

Statistical analysis. The cases and controls were compared using Student's t-test for continuous variables and the Chi-square $\left(\chi^{2}\right)$ test for categorical variables. Hardy-Weinberg equilibrium was tested with a goodness-of-fit $\chi^{2}$ test with one degree of freedom to compare the observed with the expected genotypic frequencies among the subjects. Comparison of the DNMT3B genotype and allelotype distribution in the study groups was performed by means of two-sided contingency tables using the $\chi^{2}$ test or Fisher's exact test. Unconditional logistic regression analysis was used to calculate the odds ratio (OR) and $95 \%$ confidence interval (CI), with adjustment for age and gender accordingly. $\mathrm{P}<0.05$ was considered to indicate a statistically significant difference.

\section{Results}

The $-579 \mathrm{G}>\mathrm{T}$ polymorphism in the promoter of the DNMT3B gene was first investigated in the Northeastern Chinese healthy controls and patients with lung cancer by PCR-RFLP. The characteristics of the 174 lung cancer patients and 135 control subjects are summarized in Table I. The median age of the lung cancer patients was comparable to that of the healthy controls $(\mathrm{P}=0.052)$. The gender distribution in lung cancer patients was also similar to that in healthy controls $(\mathrm{P}=0.050)$. No significant difference was found in median age and gender, suggesting that matching based on these 2 variables was adequate. The DNMT3B -579 G>T genotypes, TT, GT and GG, were detected in the lung cancer and the control groups. The genotyping by PCR-RFLP analysis was confirmed by DNA sequencing analysis. The distributions of $-579 \mathrm{G}>\mathrm{T}$ genotypes in the Northeastern Chinese population of healthy controls and lung cancer patients from the North of China are shown in Table II. The $\mathrm{G}$ allele frequency of $-579 \mathrm{G}>\mathrm{T}$ was $6.1 \%$ in lung cancers and $9.6 \%$ in normal individuals, respectively. The observed genotypes were in Hardy-Weinberg equilibrium in 
Table II. DNMT3B -579 G>T genotype and allele frequency among controls and cases.

\begin{tabular}{lcccc}
\hline & GG & GT & TT & $\begin{array}{c}\text { G allele } \\
\text { frequency }(\%)\end{array}$ \\
\hline Controls & $0(0.0)$ & $26(19.3)$ & $109(80.7)$ & 9.6 \\
Cases & $1(0.6)$ & $20(11.0)$ & $160(88.4)$ & 6.08 \\
\hline
\end{tabular}

both the cases (Pearson's $\chi^{2}=1.00, \mathrm{P}=1.00$ ) and the controls (Pearson's $\chi^{2}=1.176, \mathrm{P}=0.451$ ).

The frequency of the $G$ allele of the DNMT3B gene promoter $-579 \mathrm{G}>\mathrm{T}$ was different from previous studies in various populations (Table III). The distribution difference of the $-579 \mathrm{G}>\mathrm{T}$ genotype between the controls of various populations are summarized in Table III. The frequency of the $\mathrm{G}$ allele in the Chinese population varied from that in the Korean population. No significant difference was found in the distribution of the $-579 \mathrm{G}>\mathrm{T}$ genotype in Chinese populations from Northern China and the Jiangsu Province area.

The DNMT3B -579 G>T polymorphism was evaluated in relation to the risk of lung cancer in this case-control study. Lung cancer risks related to the DNMT3B -579 G>T genotype are shown in Table IV. The allele frequency of $-579 \mathrm{G}$ among lung cancer patients and controls was 6.1 vs. 9.6\%, respectively. The distributions of the $-579 \mathrm{G}>\mathrm{T}$ genotypes in the lung cancer group (TT, 88.5\%; GT, $10.9 \%$; and GG, $0.6 \%$ ) were significantly different from those among the controls. The OR and their $95 \%$ CIs were calculated using the more common homozygous variant genotype as the reference group (-579 TT genotypes). Compared to the reference group, the GT genotype had a decreased risk of lung cancer (OR, 0.517; 95\% CI, 0.273-0.981; $\mathrm{P}=0.041$ ). When the analyses were stratified by the age and gender of the patients, the GT or GT+GG genotypes had no significant differences associated with the risk of lung cancer, as outlined in Table V. Subsequently, in order to explore whether this SNP is associated with lung cancer patients with smoking history, we analyzed the frequency of $-579 \mathrm{G}>\mathrm{T}$ in the investigated subjects, as shown in Table VI. GT genotype individuals had a lower risk of lung cancer (OR, 0.138; 95\% CI, 0.034-0.549; $\mathrm{P}=0.001$ ).

Therefore, our data reveal key evidence that the presence of $579 \mathrm{G}>\mathrm{T}$ shows that there is a decreased likelihood of carcinogenesis occurring in lung cancer patients, at least in the studied Chinese population.

\section{Discussion}

DNMTs mediate DNA methylation, which has been reported to play a significant role in the development and progression of lung cancer $(26,27)$. DNMT3A and DNMT3B function as de novo methyltransferases, which reportedly methylate unmethylated and hemimethylated DNA with equal efficiencies (28). SNPs are the most common form of human genetic variation, and may contribute to an individuals' susceptibility to cancer. Polymorphisms of the DNMT gene may affect DNMT activity and modulate susceptibility to cancer $(25,29)$. DNMT3B has been shown to play a crucial role in tumorigenesis by incorporating de novo hypermethylation of promoter $\mathrm{CpG}$ islands, a feature that has been identified as a possible mechanism for

Table III. DNMT3B -579 G>T promoter genotype and allele frequency in various populations.

\begin{tabular}{lcccc}
\hline & TT & GT & GG & G allele frequency (\%) \\
\hline American (32) & $137(16.3)$ & $401(47.6)$ & $305(36.2)$ & 83.7 \\
\hline Korean (33) & $7(1.6)$ & $108(25.0)$ & $317(73.4)$ & 14.1 \\
Northern Chinese & $0(0.0)$ & $43(16.9)$ & $212(83.1)$ & $8.4^{\mathrm{a}, \mathrm{c}}$ \\
Jiangsu Chinese (22) & $1(0.5)$ & $40(19.0)$ & $169(80.5)$ & $10.0^{\mathrm{b}}$ \\
\hline
\end{tabular}

${ }^{\mathrm{a}} \mathrm{P}=0.009$, vs. Korean; ${ }^{\mathrm{b}} \mathrm{P}=0.524$, vs. Northern Chinese; ${ }^{\mathrm{c}} \mathrm{P}<0.01$, vs. American.

Table IV. DNMT3B 579 G>T genotype and allele frequencies and their association with lung cancer.

\begin{tabular}{|c|c|c|c|c|c|c|}
\hline \multirow[t]{2}{*}{ Genotype } & \multicolumn{2}{|c|}{$\begin{array}{l}\text { Lung cancer } \\
\qquad(\mathrm{n}=174)\end{array}$} & \multicolumn{2}{|c|}{$\begin{array}{l}\text { Control subjects } \\
\qquad(n=135)\end{array}$} & \multirow[t]{2}{*}{$\begin{array}{l}\text { Crude OR } \\
(95 \% \mathrm{CI})\end{array}$} & \multirow[t]{2}{*}{ P-value } \\
\hline & No. & $\%$ & No. & $\%$ & & \\
\hline \multicolumn{7}{|l|}{$579 \mathrm{G}>\mathrm{T}$} \\
\hline TT (ref.) & 154 & 88.5 & 109 & 80.7 & 1 & \\
\hline GT & 19 & 10.9 & 26 & 19.3 & $0.517(0.273-0.981)$ & 0.041 \\
\hline GG & 1 & 0.6 & 0 & 0 & & \\
\hline $\mathrm{GT}+\mathrm{GG}$ & 20 & 11.5 & 26 & 19.3 & $0.544(0.289-1.025)$ & 0.057 \\
\hline $\mathrm{G}$ allele & - & 6.08 & & & & \\
\hline
\end{tabular}


Table V. Distribution of -579 G>T DNMT3B genotypes and associated ORs in relation to age and gender in LC cases.

\begin{tabular}{|c|c|c|c|c|}
\hline Genotype & $\mathrm{LC}$ & Controls & OR & P-value \\
\hline \multicolumn{5}{|c|}{ Age (years) } \\
\hline \multicolumn{5}{|l|}{$<45$} \\
\hline $\mathrm{TT}$ & $25(100)$ & $26(83.9)$ & 1.0 & \\
\hline GT & $0(0.0)$ & $5(16.1)$ & & \\
\hline GG & $0(0.0)$ & $0(0.0)$ & & \\
\hline \multicolumn{5}{|l|}{$\geq 45$} \\
\hline $\mathrm{TT}$ & $129(86.5)$ & $83(79.8)$ & 1.0 & \\
\hline GT & $19(12.8)$ & $21(20.2)$ & $0.582(0.295-1.148)$ & 0.116 \\
\hline GG & $1(0.7)$ & $0(0.0)$ & & \\
\hline \multicolumn{5}{|l|}{ Gender } \\
\hline \multicolumn{5}{|l|}{ Male } \\
\hline $\mathrm{TT}$ & $94(87.9)$ & $82(82)$ & 1.0 & \\
\hline GT & $13(12.1)$ & $18(18)$ & $0.533(0.234-1.218)$ & 0.132 \\
\hline GG & $0(0.0)$ & $0(0.0)$ & & \\
\hline \multicolumn{5}{|l|}{ Female } \\
\hline TT & $61(91.0)$ & $124(83.8)$ & 1.0 & \\
\hline GT & $5(7.5)$ & $24(16.2)$ & $0.376(0.124-1.134)$ & 0.074 \\
\hline GG & $1(1.5)$ & $0(0.0)$ & & \\
\hline
\end{tabular}

OR, odds ratio; LC, lung cancer.

Table VI. Distribution of 579 G>T DNMT3B genotypes and associated OR in relation to smoking history.

\begin{tabular}{lcccc}
\hline Genotype & LC $(\%)$ & Controls $(\%)$ & OR & P-value \\
\hline Smoking & 48 & 16 & 1 & $0.138(0.034-0.549)$ \\
TT & 3 & 9 & & \\
GT & 0 & 0 & 1 \\
GG & & & & \\
No smoking & 106 & 93 & & \\
TT & 16 & 17 & 001 \\
GT & 1 & 0 & & \\
GG & & & & \\
\hline
\end{tabular}

OR, odds ratio; LC, lung cancer.

TSG inactivation within human cancer cells (30). A number of previous studies on DNMT3B gene SNPs and lung cancer have implied that polymorphisms of DNMT3B are associated with a significantly increased risk of lung cancer $(31,32)$. In genes, a promoter region may initiate translation and raise the risk of cancer by influencing the expression or activity levels of enzymes $(18,33)$. In previous studies, it has been confirmed that $579 \mathrm{G}>\mathrm{T}$ is located at the promoter region of DNMT3B and the $\mathrm{T}$ transversion affects the activity of the DNMT3B promoter (34). Previously, contradictory conclusions have been made regarding the association of the $-579 \mathrm{G}>\mathrm{T}$ polymorphism with various cancers. Previous studies have revealed that $-579 \mathrm{G}>\mathrm{T}$ polymorphisms have no association with esophageal cancer and head and neck squamous cell carcinoma $(25,35)$, but that they may be an indication of gastric cancer (22).
In the present study, we focused on the significance of $-579 \mathrm{G}>\mathrm{T}$ of the DNMT3B polymorphism to lung cancer in a Northeastern Chinese population. The frequency of the $G$ allele in the lung cancer cases was lower than that in the controls. There was a significant difference in GT allele between the lung cancer patients and the controls. SNPs of the DNMT3B promoter $-579 \mathrm{G}>\mathrm{T}$ may decrease the susceptibility of an individual to lung cancer, suggesting that the DNMT3B promoter $-579 \mathrm{G}>\mathrm{T}$ polymorphism may be used as an indicator to evaluate susceptibility to lung cancer. Stratified by age and gender in the investigated subjects, no significant association was found between the $-579 \mathrm{G}>\mathrm{T}$ polymorphism and the risk of lung cancer in this population. However, when stratifying the results by smoking, the $-579 \mathrm{G}>\mathrm{T}$ genotypic frequency was significantly different, suggesting that the $579 \mathrm{G}>\mathrm{T}$ poly- 
morphism may be used as a marker for lung cancer diagnosis among smokers. The results also revealed that the difference was fairly significant between Korean and Northern Chinese populations, but that no clear difference was observed between populations from Northern China and the Jiangsu Province. This may suggest that there are deviations among various ethnic groups.

Since it has been noted that individuals with the $G$ allele in DNMT3B share an almost consistent rate of lung cancer compared with those carrying the $\mathrm{T}$ allele, it can be stated that the repression of DNMT3B activity does not lead to re-expression of all hypermethylated TSGs in lung cancer (36). However, when taking smoking factors into consideration, the down-regulated DNMT3B results in the re-expression of TSGs (37). It has been suggested that an interaction of environment and genes contributes to lung cancer susceptibility. Moreover, the exact mechanisms of DNMT3B SNPs involved in tumorigenesis still require further studies.

In conclusion, the $-579 \mathrm{G}>\mathrm{T}$ polymorphism in the DNMT3B gene may be a potential indication for diagnosis in the development of lung cancer. Combined with smoking, the polymorphism may facilitate the diagnosis of lung cancer. Further studies with larger number of samples are required to confirm and develop our findings. The role of DNMTs, SNPs and their relationships with various cancers require further clarification.

\section{Acknowledgements}

This study was supported by the Qinglan Project of the Jiangsu province of China (2006). The authors would like to thank Ming Shi, Zhenhao Zhang, Jianting Liang and TingTing Bo for their help with extracting the genomic DNA.

\section{References}

1. Yang L, Parkin DM, Li LD, et al: Estimation and projection of the national profile of cancer mortality in China. Br J Cancer 90: 2157-2166, 2004

2. Amos CI, Wu X, Broderick P, et al: Genome-wide association scan of tag SNPs identifies a susceptibility locus for lung cancer at 15q25.1. Nat Genet 40: 616-622, 2008.

3. Hung RJ, McKay JD, Gaborieau V, et al: A susceptibility locus for lung cancer maps to nicotinic acetylcholine receptor subunit genes on 15q25. Nature 452: 633-637, 2008.

4. Thorgeirsson TE, Geller F, Sulem P, et al: A variant associated with nicotine dependence, lung cancer and peripheral arterial disease. Nature 452: 638-642, 2008.

5. Kim, DH, Nelson HH, Wiencke JK, et al: p16 (INK4a) and histology-specific methylation of $\mathrm{CpG}$ islands by exposure to tobacco smoke in non-small cell lung cancer. Cancer Res 61: 3419-3424, 2001.

6. Toyooka S, Maruyama R, Toyooka KO, McLerran D, Feng Z, Fukuyama Y, Virmani AK, Zochbauer-Muller S, Tsukuda K, Sugio K, et al: Smoke exposure, histologic type and geographyrelated differences in the methylation profiles of non-small cell lung cancer. Int J Cancer 103: 153-160, 2003.

7. Jones PA and Laird PW: Cancer epigenetics comes of age. Nature Genet 21: 163-167, 1999.

8. Baylin SB and Herman JG: DNA hypermethylation in tumorigenesis; epigenetics joins genetics. Trends Genet 16: 168-171, 2000

9. Cooper DN and Youssoufian $\mathrm{H}$ : The $\mathrm{CpG}$ dinucleotide and human genetic disease. Hum Genet 78: 151-155, 1988

10. Yen RW, Vertino PM, Nelkin BD, et al: Isolation and characterization of the cDNA encoding human DNA methyltransferase, Nucleic Acids Res 20: 2287-2291,1992.

11. Xie S, Wang Z, Okano M, et al: Cloning: expression and chromosome locations of the human DNMT3 gene family. Gene 236: 87-95, 1999.
12. Bestor TH: The DNA methyltransferases of mammals. Hum Mol Genet 9: 2395-2402, 2000.

13. OkanoM, Bell DW, Haber DA and Li E: DNA methyltransferases Dnmt3a and Dnmt3b are essential for de novo methylation and mammalian development. Cell 99: 247-257, 1999.

14. Robertson KD: DNA methylation, methyltransferases, and cancer. Oncogene 20: 3139-3155, 2001.

15. Gonzalgo ML and Jones PA: Mutagenic and epigenetic effects of DNA methylation. Mutat Res 386: 107-118, 1997.

16. Takeshima H, Suetake I, Shimahara H, et al: Distinct DNA methylation activity of Dnmt3a and Dnmt3b towards naked and nuclosomal DNA. J Biochem. 139: 503-515, 2006.

17. Cebrian A, Pharoah PD, Ahmed S, et al: Genetic variants in epigenetic genes and breast cancer risk. Carcinogenesis 27: $1661-1669,2006$

18. Simão Tde A, Simões GL, Ribeiro FS, et al: Lower expression of p14ARF and p16INK4a correlates with higher DNMT3B expression in human oesophageal squamous cell carcinomas. Hum Exp Toxicol 25: 515-552, 2006.

19. Hong YS, Lee HJ, You CH, et al: DNMT3B 39179GT polymorphism and the risk of adenocarcinoma of the colon in Koreans. Biochem Genet 45: 155-163, 2007.

20. Palakurthy RK, Wajapeyee N, Santra MK, et al: Epigenetic silencing of the RASSF1A tumor suppressor gene through HOXB3-mediated induction of DNMT3B expression. Mol Cell 36: 219-230, 2009.

21. Lin RK, Hsu HS, Chang JW, et al: Alteration of DNA methyltransferases contributes to $5^{\prime} \mathrm{CpG}$ methylation and poor prognosis in lung cancer. Lung Cancer 55: 205-213, 2007.

22. Hu J, Fan H, Liu D, et al: NMT3B Promoter polymorphism and risk of gastric cancer. Diq Dis Sci 55: 1011-1016, 2010.

23. Chang KP, Hao SP, Liu CT, et al: Promoter polymorphisms of DNMT3B and the risk of head and neck squamous cell carcinoma in Taiwan: a case-control study. Oral Oncol 43: 345-351, 2007.

24. Miller SA, Dykes DD and Polesky HF: A simple salting out procedure for extracting DNA from human nucleated cells. Nucleic Acids Res 16: 1215, 1988.

25. Lee SJ, Jeon HS, Jang JS, et al: DNMT3B polymorphisms and risk of primary lung cancer. Carcinogenesis 26: 403-409, 2005.

26. Kim EH, Park AK, Dong SM, et al: Global analysis of CpG methylation reveals epigenetic control of the radiosensitivity in lung cancer cell lines. Oncogene 29: 4725-4731, 2010.

27. Pfeifer GP and Rauch TA: DNA methylation patterns in lung carcinomas. Semin Cancer Biol 19: 181-187, 2009.

28. Hsieh CL: Dynamics of DNA methylation pattern. Curr Opin Genet Dev 10: 224-228, 2000.

29. Fan H, Liu D, Qiu X, et al: A functional polymorphism in the DNA methyltransferase-3A promoter modifies the susceptibility in gastric cancer but not in esophageal carcinoma. BMC Med 8: $12,2010$.

30. Momparler RL and Bovenzi V: DNA methylation and cancer. J Cell Physiol 183: 145-154, 2000.

31. Shen H, Wang L, Spitz MR, et al: A novel polymorphism in human cytosine DNA-methyltransferase-3B promoter is associated with an increased risk of lung cancer. Cancer Res 62: 4992-4995, 2002.

32. Skoog T, van't Hooft FM, Kallin B, et al: A common functional polymorphism $(\mathrm{C} \rightarrow \mathrm{A}$ substitution at position -863) in the promoter region of the tumor necrosis factor-alpha (TNF-alpha) gene associated with reduced circulating levels of TNF-alpha. Hum Mol Genet 8: 1443-1449, 1999.

33. Singal R, Das PM, Manoharan M, et al: polymorphisms in the DNA methyltransferase 3B gene and prostate cancer risk. Oncol Rep 14: 569-573, 2005.

34. Fan H, Liu DS, Zhang SH, et al: DNMT3B $579 \mathrm{G}>\mathrm{T}$ promoter polymorphism and risk of esophagus carcinoma in Chinese. World J Gastroenterol 14: 2230-2234, 2008.

35. Liu Z, Wang L, Wang LE, et al: Polymorphisms of the DNMT3B gene and risk of squamous cell carcinoma of the head and neck: a case-control study. Cancer Lett 268: 158-165, 2008.

36. Wang J, Bhutani M, Pathak AK, et al: Delta DNMT3B variants regulate DNA methylation in a promoter-specific manner. Cancer Res 67: 10647-10652, 2007.

37. Liu H, Zhou Y, Boggs SE, et al: Cigarette smoke induces demethylation of prometastatic oncogene synuclein-gamma in lung cancer cells by downregulation of DNMT3B. Oncogene 26: 5900-5910, 2007. 